\title{
Effect of an educational intervention on HPV knowledge and vaccine attitudes among urban employed women and female undergraduate students in China: a cross-sectional study
}

Irene J Chang ${ }^{1,2}$, Rong Huang', Wei He' ${ }^{1}$, Shao-Kai Zhang ${ }^{1}$, Shao-Ming Wang ${ }^{1}$, Fang-Hui Zhao ${ }^{1 *}$, Jennifer S Smith ${ }^{3}$ and You-Lin Qiao ${ }^{1}$

\begin{abstract}
Background: Due to the potential of human papillomavirus (HPV) vaccination for decreasing cervical cancer rates in Mainland China, where some of the highest incidences in the world have been reported, our study aimed to assess HPV and HPV vaccine knowledge, and to evaluate the effect of a brief educational intervention on HPV knowledge and vaccine acceptability in Chinese undergraduate students and employed women.

Methods: This multi-center, cross-sectional study was conducted across five representative cities of the five main geographical regions of Mainland China. Participants were selected from one comprehensive university and three to four companies in each city for a total of six comprehensive universities and 16 companies. A 62-item questionnaire on HPV knowledge and HPV vaccine acceptability was administered to participants before and after an educational intervention. The intervention consisted of an informative group lecture.

Results: A total of 1146 employed women and 557 female undergraduate students were surveyed between August and November 2011. Baseline HPV knowledge was low among both groups-320/1146 (28\%) of employed women and 66/557 (12\%) of students had heard of HPV, while only 237/1146 (21\%) of employed women and 40/ $557(7.2 \%)$ of students knew that HPV is related to cervical cancer. After educational instruction, 947/1061 (89\%) of employed women and 193/325 (59\%) of students knew the relationship between HPV and cervical cancer ( $X 2=$ $1041.8, p<0.001$ and $x 2=278.5, p<0.001$, respectively). Post-intervention, vaccine acceptability increased from $881 / 1146(77 \%)$ to $953 / 1061(90 \%),(p=<0.001)$ in employed women and 405/557 (73\%) in students to 266/325 $(82 \%),(p<0.001)$. Women in both groups cited concerns about the HPV vaccine's safety, efficacy, and limited use to date as reasons for being unwilling to receive vaccination. 502/1146 (44\%) of women were willing to vaccinate their children at baseline, which increased to 857/1061 (81\%) post-intervention, $\mathrm{p}<0.001$.

Conclusions: Incorporation of our lecture-based education initiative into a government-sponsored or school-based program may improve HPV-related knowledge and HPV vaccine acceptability. Further studies are needed to evaluate and standardize HPV education programs in China.
\end{abstract}

Keywords: Cervical cancer, HPV education, Human papillomavirus, Prophylactic HPV vaccine, HPV knowledge, HPV attitudes, Vaccine acceptability

\footnotetext{
* Correspondence: zhaofangh@cicams.ac.cn

'Department of Epidemiology, Cancer Institute of Chinese Academy of

Medical Sciences, Peking Union Medical College, Beijing, P.R. China

Full list of author information is available at the end of the article
} 


\section{Background}

Despite recent strides made in HPV vaccination and education, over half a million women worldwide develop cervical cancer each year. Over $85 \%$ of these cases occur in developing countries such as China due to the lack of effective screening and prevention programs [1,2]. The incidence of cervical cancer in Mainland China increased from 5.14 persons per 100,000 in 2004 to 6.87 persons per 100,000 in 2008 [3-5]. Persistent infection with highrisk human papillomavirus (hrHPV) subtypes has been established as the primary cause of squamous cell cervical cancer [6]. In China, HPV 16 and 18 are implicated in the etiology of over $84.5 \%$ of cervical malignancies $[7,8]$.

Both the bivalent and quadrivalent HPV vaccines have been demonstrated to effectively prevent the development of high-grade cervical neoplasias, particularly when given to girls before they become sexually active [9-12]. The prophylactic HPV vaccines currently undergoing clinical trials in Mainland China hold potential to significantly decrease cervical cancer mortality rates in the future. Prior to the licensure and widespread use of these vaccines, HPV education plays a crucial role in vaccine acceptability in the general population [13]. Studies have demonstrated that mothers with higher HPV knowledge have increased vaccine uptake and express greater willingness to vaccinate their children $[14,15]$.

Previous studies on knowledge and attitudes about HPV among different groups of Chinese women have revealed high vaccine acceptability but low levels of knowledge about HPV and cervical cancer [16]. A pilot study by Kwan et al. (2008) demonstrated only 38\% of women in Hong Kong had heard of HPV [17]. Zhao et al. (2012) confirmed that knowledge about HPV was similarly low in Mainland China, with $34 \%$ of urban women, $16 \%$ of rural women, and $44 \%$ of government officials having heard of HPV. Of concern, less than 20\% of healthcare workers correctly identified the ideal time for HPV vaccination as prior to sexual debut [18]. These data suggest a strong need for HPV and HPV vaccine education in the general female population in Mainland China.

In recent years, there has been a proliferation of HPV education studies internationally. Educational instruction on HPV-related diseases has been demonstrated to effectively raise HPV knowledge and vaccine acceptability in America [19,20], Sweden [21], Korea [22], and Turkey [23,24]. Although previous studies have assessed the effect of education instruction on HPV-related knowledge in Hong Kong [25-27], the differing socioeconomic factors and the availability of the HPV vaccine in Hong Kong make the findings less applicable to Mainland China. In our present study, we report the results of a multi-center study examining the effect of a brief educational intervention on HPV vaccine-related knowledge and attitudes among employed women and undergraduate female students in Mainland China.

\section{Methods}

\section{Participants and recruitment}

This was a multi-center, cross-sectional study across the five main geographical regions of Mainland China. One large, economically developed city was selected from each of the five geographic regions of China (northern Beijing, eastern Hangzhou, central Changsha, southwestern Chengdu, and southern Guangzhou). Participants were then selected from one comprehensive university and three to four companies in each city for a total of six comprehensive universities and 16 companies. Participants were recruited by flyers and poster announcements in lecture halls, student centers, and the employment units at local companies.

\section{Informed consent}

Prior to enrollment, all participants were fully informed about the objectives of the study, benefits and risks associated with participation, and assured of the confidentiality of the information they provide. After informed consent was obtained, a 62-item, multiple-choice questionnaire was administered to participants. The questionnaire was adapted from those based on expert opinions and used in previous studies among different populations across Mainland China [16,18]. The same questionnaire was administered again following the educational intervention to assess differences in HPV knowledge and vaccine attitudes. This study was approved by the Institutional Review Board of the Cancer Institute, Chinese Academy of Medical Sciences (CICAMS).

\section{Educational intervention}

The educational intervention consisted of a one-hour group lecture followed by the same questionnaire as the one given after informed consent. Questions were written in Mandarin Chinese in simple terms appropriate for the level of education of the participants as previously validated $[16,18]$. Participants were encouraged to complete the questionnaire independently and trained staff members stood by to answer any questions participants had. The study flowchart is shown in Figure 1.

\section{Statistical analysis}

The data manager organized the database using EpiData 3.1. To ensure accuracy, two different research members entered data separately. Data analysis was performed using SPSS software version 18.0. Chi-square or F-test analysis was performed on the demographic characteristics of participants such as age, occupation, and geographic region. Multivariate analysis of all descriptive factors was performed to compare pre- and post-interventional 


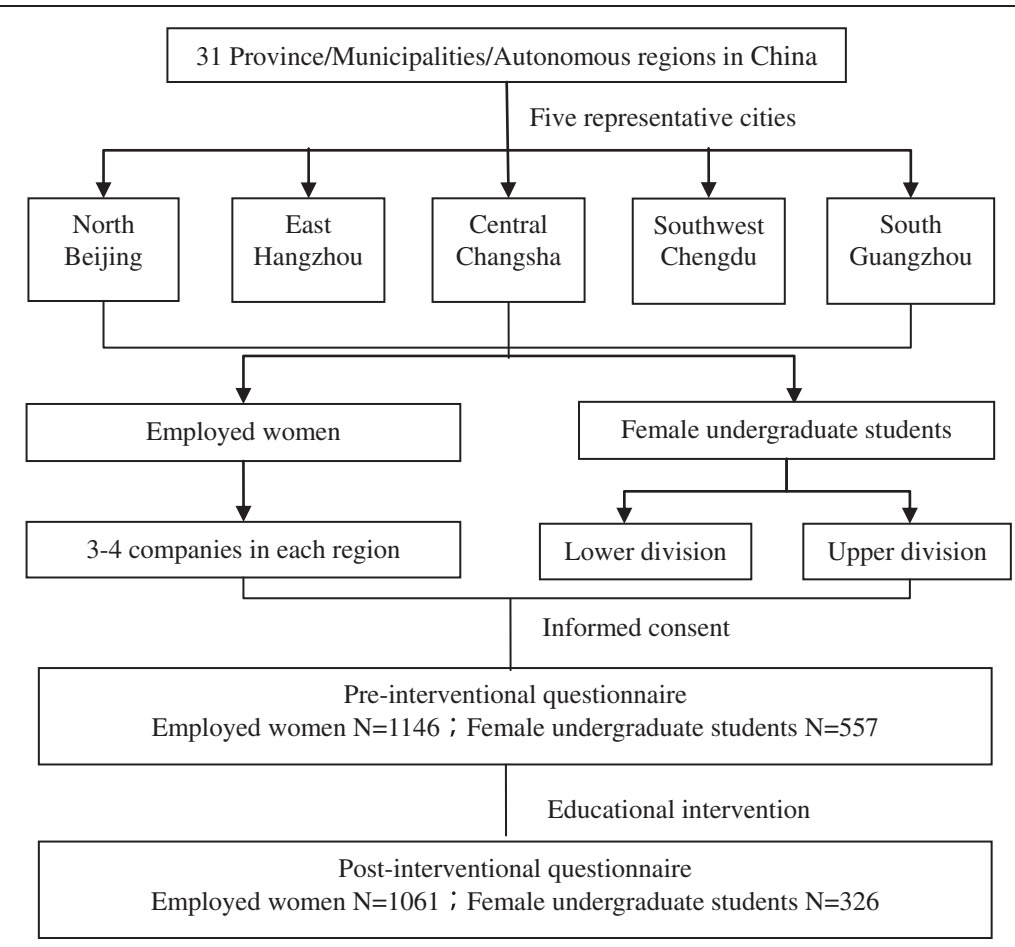

Figure 1 Study flowchart.

HPV and vaccine knowledge. Logistic regression was performed to analyze the association between potential predictor variables and willingness to receive vaccination. Odds ratios (ORs) with 95\% confidence intervals (CIs) were calculated based on Wald Chi-square statistics. Statistical significance was set at $\mathrm{p}<0.05$.

\section{Results}

From August to November of 2011,1146 employed women and 557 female undergraduate students were surveyed. After excluding incomplete questionnaires, 1061 and 325 surveys were included in the post-interventional analysis, respectively.

\section{Demographics}

Table 1 shows demographic and medical information about the participants. Average age of $37.0 \pm 10$ for employed women and $20.4 \pm 1.2$ for undergraduate students. Among the undergraduate students, 385/557 (70\%) were underclassmen and 163/557 (30\%) were upperclassmen.

\section{Pre-intervention HPV- related knowledge}

At baseline, 1089/1146 (95\%) of employed women and 440/557 (79\%) of female undergraduate students had heard of cervical cancer. However, HPV knowledge was low in both groups, with only 321/1146 (28\%) of employed women and 66/557 (12\%) female students having heard of HPV. 237/1146 (21\%) of employed women and 40/557 (7.2\%) of students knew that HPV infection causes cervical cancer, but only 51/1146 (4.5\%) and 18/557 (3.2\%) knew the association between HPV and genital warts, respectively. Similarly, only 147/1146 (13\%) employed women and $62 / 557$ (11\%) students had heard of the HPV vaccine. $212 / 1146(18 \%)$ and $69 / 557$ (12\%) knew that the vaccine could prevent cervical cancer, respectively. 103/1146 (9\%) of employed women were not concerned about developing cervical cancer. Knowledge of HPV and cervical cancer did not differ significantly between women from different geographical regions $(\mathrm{p}>0.05)$. Baseline HPV knowledge is summarized in Figure 2.

\section{Post-interventional HPV-related knowledge}

After a brief educational narrative about HPV and cervical cancer, HPV-related knowledge increased significantly. Comparison of pre- and post-interventional HPV knowledge is shown in Figure 3. Post-intervention, 947/1061 (89\%) of employed women knew that HPV infection caused cervical cancer from 237/1146 (21\%) at baseline, a 4.2 fold increase from baseline $\left(\chi^{2}=1041.8, \mathrm{p}<0.001\right)$. Among undergraduate students, knowledge of this causal relationship increased over seven-fold from 40/557 (7.2\%) to $193 / 325$ (59\%), $\left(\chi^{2}=278.5, \mathrm{p}<0.001\right)$.

Post-interventional knowledge about HPV-related diseases and risk factors for HPV infection also increased significantly. In particular, correct identification of the ideal time for HPV vaccination as prior to sexual debut increased significantly from 246/1146 (21\%) to $725 / 1061$ (68\%) in employed women and 205/557 (37\%) 
Table 1 Characteristics of employed women and female undergraduate students

\begin{tabular}{|c|c|c|}
\hline Characteristics & $\begin{array}{c}\text { Employed } \\
\text { women (n, \%) }\end{array}$ & $\begin{array}{l}\text { Undergraduate } \\
\text { students (n, \%) }\end{array}$ \\
\hline Total participants (N) & 1146 & 557 \\
\hline Age (years, mean $\pm S D$ ) & $37.0 \pm 10.0$ & $20.4 \pm 1.2$ \\
\hline Age at menarche (years, mean $\pm S D$ ) & $13.6 \pm 13.0$ & $13.1 \pm 1.3$ \\
\hline \multicolumn{3}{|l|}{ Education level } \\
\hline$<$ High school & $408(35.6)$ & - \\
\hline$\geq$ Some college & $703(61.3)$ & - \\
\hline \multicolumn{3}{|l|}{ University grade* } \\
\hline Lower classmen & - & $385(69.1)$ \\
\hline Upper classmen & - & $163(29.3)$ \\
\hline \multicolumn{3}{|l|}{ Number of lifetime sexual partners } \\
\hline 1 & $668(58.3)$ & - \\
\hline$\geq 2$ & $87(7.6)$ & - \\
\hline \multicolumn{3}{|l|}{ Contraceptive method } \\
\hline None & $520(45.3)$ & - \\
\hline Condoms (barrier method) & $438(38.2)$ & - \\
\hline \multicolumn{3}{|l|}{ Undergoes regular gynecologic exam } \\
\hline Yes & $868(75.7)$ & - \\
\hline No & $178(15.5)$ & - \\
\hline \multicolumn{3}{|l|}{ History of genital tract infections } \\
\hline Yes & $408(35.6)$ & - \\
\hline No & $524(45.7)$ & - \\
\hline \multicolumn{3}{|l|}{ Obstetric history } \\
\hline Nulliparous & $425(37.1)$ & - \\
\hline 1 live birth & $664(57.9)$ & - \\
\hline$\geq 2$ live births & $57(5.0)$ & - \\
\hline \multicolumn{3}{|l|}{ Regions } \\
\hline North/Beijing & $245(21.4)$ & $197(35.4)$ \\
\hline East/Hangzhou & $248(21.6)$ & $64(11.5)$ \\
\hline Central/Changsha & $229(20.0)$ & $33(5.9)$ \\
\hline Southwest/Chengdu & $176(15.4)$ & $67(12.0)$ \\
\hline South/Guangzhou & $248(21.6)$ & $196(35.2)$ \\
\hline
\end{tabular}

*Underclassmen refers to first- and second-year undergraduate students, upperclassmen refers to third- and fourth-year undergraduate students.

to $223 / 325$ (69\%), $\left(\chi^{2}=79.6, \mathrm{p}<0.001\right)$ in female students. Employed women also reported increased intention to undergo routine gynecologic exam after the intervention from 601/1146 (52\%) to 974/1061 (92\%), ( $<<0.001)$.

\section{Attitudes and acceptability towards the HPV vaccine}

Willingness to receive HPV vaccination increased significantly post-intervention from 881/1146 (77\%) to 953/1061 (90\%) in employed women and from 405/557 (73\%) to 266/325 (82\%) in students, $(\mathrm{p}<0.01)$. Female undergraduate students over age 20 were 1.6 times more willing to receive vaccination (0.9-2.9) than those under age 20. Knowledge of cervical cancer, concern about contracting cervical cancer, and approval of widespread usage of the vaccine were factors that influenced willingness to receive vaccination (OR 2.4 (1.3-4.8), 2.8 (1.6-5.0), and 4.3 (2.4-7.6), respectively). 265/1146 (23\%) of employed women and $152 / 557$ (27\%) of female undergraduate students were unwilling to receive vaccination for themselves. The most common reasons against vaccination given by both groups of participants was concern about vaccine safety (325/ 1146 (58\%) in women and 459/557 (40\%) in students), concern about vaccine efficacy $(331 / 1146(29 \%)$ in women and 238/557 (43\%) in students), and limited usage of the vaccine to date $(258 / 1146(23 \%)$ in women and $177 / 557$ (32\%) in students). Baseline attitudes and vaccine acceptability are shown in Figure 2 and comparison of pre- and post-interventional vaccine acceptability are shown in Figure 3.

Post-intervention, willingness of employed women to vaccinate their children increased from 502/1146 (44\%) to $857 / 1061$ (81\%), $\left(\chi^{2}=261.7, \mathrm{p}<0.001\right)$. However, $175 / 1061$ (16\%) women were still unwilling to vaccinate their children after educational instruction due to concerns about vaccine safety $(249 / 1061(24 \%))$, concerns about vaccine efficacy $(136 / 1061(13 \%))$, and belief that their children are too young to be at risk (233/1061 (22\%)). Comparison of pre- and post-educational HPV vaccine attitudes is shown in Figure 3.

Logistic regression examining the effect of various sociodemographic predictors and cervical cancer risk on maternal willingness to vaccinate their children is presented in Table 2. Women were more likely to be willing to vaccinate their children if they were between the ages of 36 to 45 (OR $=0.35(0.18-0.68), \mathrm{p}=0.002)$ and if they were concerned about contracting cervical cancer themselves $(\mathrm{OR}=1.8$ (1.1-3.2), $\mathrm{p}=0.03)$. Overall, 902/ 1703 (53\%) of all participants chose the China Center for Disease Control and 426/1703 (25\%) chose women and children's hospitals as the ideal location to receive the HPV vaccine.

\section{Discussion}

The brief educational intervention in our study effectively raised HPV and HPV vaccine knowledge in undergraduate students and employed women, and also increased vaccine acceptability. Post-intervention, women were twice as likely to report willingness to vaccinate their children and correctly identified younger ages as ideal for receiving the HPV vaccine. This is of particular significance because a recent study suggests for optimal vaccine compliance, girls in China should be vaccinated between the ages of 13-15, prior to concluding their mandatory schooling and becoming sexually active [18]. 


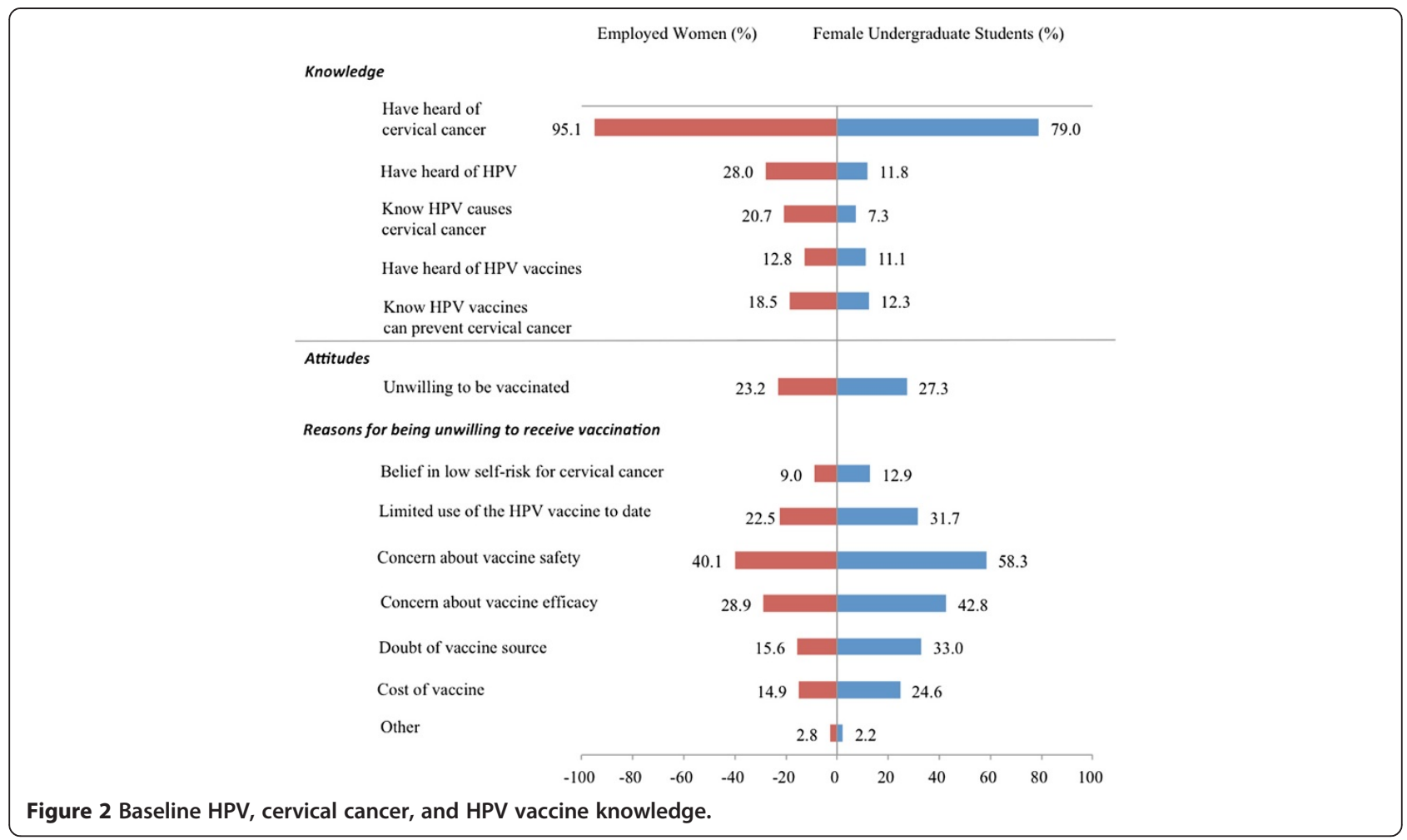

While the HPV vaccine may reduce the incidence of cervical cancer in the future, clinical trials across China are ongoing. An effective HPV education program that addresses specific knowledge gaps and common questions among women of different regions, education levels, and cultures has been demonstrated to increase the success of large-scale vaccination programs [21]. Studies in the U.S. have found that educational programs should emphasize vaccine effectiveness and the high likelihood of HPV infection, and address barriers to vaccination [14]. A similar study in Japan found that vaccine safety and cost should be addressed to increase maternal vaccine acceptability for their children [28]. Women also reported increased vaccine acceptability for themselves and their children after hearing physician and government endorsements of the HPV vaccine [25,28].

To our knowledge, the present study represents the first evaluation of a large-scale HPV educational intervention in Mainland China. Kwan et al. [26,27] have conducted similar HPV knowledge and education studies in Hong Kong, yet no similar educational interventions have been conducted in Mainland China. A previous study by Zhang and colleagues [18] examined HPV knowledge alone in China among the general female population, healthcare personnel, and government officials. Our results confirm their findings of low baseline HPV knowledge among employed women and female undergraduate students. In addition, our survey of employed women and female undergraduate students paints a more comprehensive picture of HPV knowledge in different female population groups across Mainland China.

The results of our present study indicate that baseline HPV knowledge is low among employed women and female undergraduate students in northern, eastern, central, southern, and southwestern regions of China. Through our study, we also gained valuable insight into the preferred methods of obtaining HPV-related information and social beliefs held among Chinese women. Employed women and female college students preferred to receive HPV-related information via school or hospital-based lectures. They also believed that a national organization such as the Center for Disease Control should be responsible for providing the vaccine. In addition, vaccine safety, efficacy, and cost remained concerns and barriers to vaccination. Women had no preference for either the domestic or foreign HPV vaccine, but believed that the government should support and partially subsidize the cost. Future HPV education programs can focus on addressing these aforementioned issues. Furthermore, over $76 \%$ of employed females believe that getting vaccinated is a societal responsibility that should be shared by both genders. Thus, a government-sponsored, school-based education program can effectively disperse safe intercourse practices and HPV vaccine information to both male and female students.

Strengths of our study include the relatively large population sampled across five main geographical regions of Mainland China. We also targeted employed women and undergraduate female students, two populations who have 


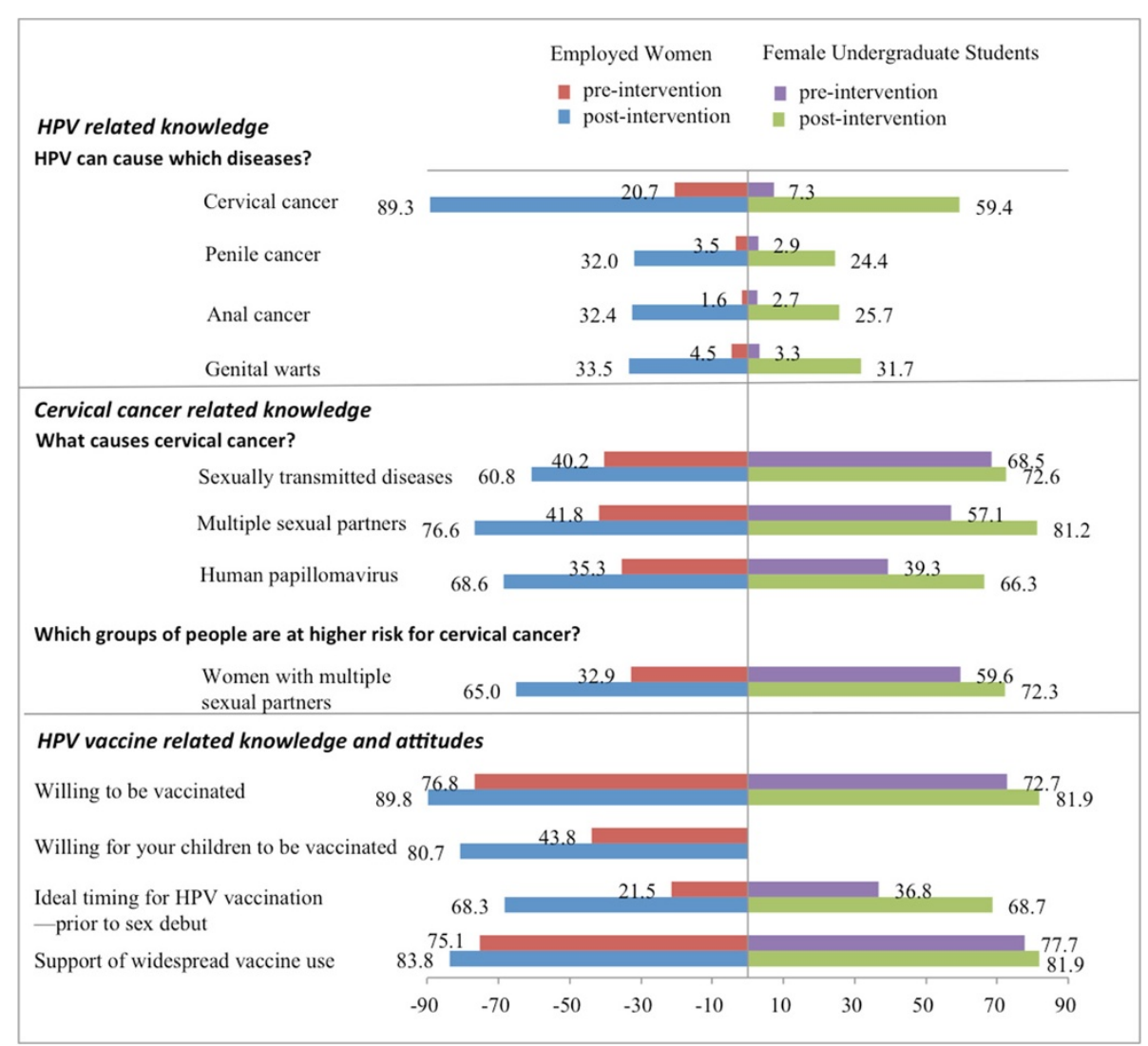

Figure 3 Comparison of pre- and post-interventional HPV-related knowledge.

not been surveyed before. Our findings are consistent with previous studies, which found that HPV knowledge and vaccine acceptability were higher among college-educated women $[18,25]$.

Limitations of our study include the cross-sectional design. While our educational intervention significantly increased post-test HPV knowledge and vaccine acceptance, the strength of causality is limited by the absence of a control group. Also, although our questionnaire was adapted from previous studies, we did not apply a scale to assess its validity. Future large-scale studies should devise a reliability scale to evaluate the questionnaire. Furthermore, our study was mainly carried out in urban centers among women with higher education levels thus due to the potential sampling bias, our findings may not be generalized to the entire Chinese population. HPV knowledge and vaccine receptivity have been shown to vary widely based on region, sociodemographic factors and education level $[14,16]$. In 2007, a survey of 400 Uyghur women in Xinjiang found only 5\% had heard of cervical cancer [29]. A more recent study in 2011 on 1005 Han, Uyghur, and Muslim women residing in Xinjiang found that only $5.2 \%$ of Uyghur women and $11.5 \%$ of Muslim women knew the association between
HPV infection and cervical cancer, suggesting that the findings of our study may not be generalized to different groups of Chinese women [30]. This highlights the need for culturally salient HPV and cervical cancer education especially among Chinese ethnic minority populations. Furthermore, while HPV and HPV vaccine knowledge significantly improved immediately following the brief educational intervention, its lasting impact is unknown. It is also uncertain whether vaccine acceptability and positive attitudes towards vaccination would persist and translate into higher vaccination rates.

\section{Conclusions}

Our study demonstrates that incorporation of our educational initiative into a government sponsored or school based program may improve willingness to accept HPV vaccination. The potential implications of our study are far-reaching during this pivotal time of HPV vaccine clinical trials in China. It is important to establish the link between HPV infection and the development of cervical cancer, and to educate women on the ideal time to vaccinate their children. Studies have shown that maternal attitudes towards vaccination greatly impacts vaccination rates among children. It is also imperative to dispel 
Table 2 Logistic regression analysis for maternal willingness to vaccinate their children

\begin{tabular}{|c|c|c|c|c|c|}
\hline \multirow[t]{2}{*}{ Characteristics of employed women } & \multirow[t]{2}{*}{$\mathbf{N}$} & \multicolumn{4}{|c|}{ Willingness to vaccinate their children } \\
\hline & & N (\%) & Ajusted OR (95\% Cl) & Walds $x^{2}$ & $\mathbf{P}$ \\
\hline \multicolumn{6}{|l|}{ Age (yrs) } \\
\hline$\leq 25$ & 164 & $61(59.2)$ & 1.00 & & \\
\hline $26-35$ & 292 & $91(37.1)$ & $1.16(0.37-3.7)$ & 0.06 & 0.80 \\
\hline $36-45$ & 282 & $96(41.2)$ & $0.35(0.18-0.68)$ & 9.45 & 0.00 \\
\hline$>45$ & 253 & $99(51.3)$ & $0.46(0.25-0.87)$ & 5.76 & 0.02 \\
\hline \multicolumn{6}{|l|}{ Education level } \\
\hline$\leq$ High school & 408 & $154(49.36)$ & 1.00 & & \\
\hline$>$ High school & 703 & $229(41.11)$ & $0.93(0.53-1.6)$ & 0.07 & 0.79 \\
\hline \multicolumn{6}{|l|}{ Occupation } \\
\hline Skilled professionals & 821 & $278(42.25)$ & 1.00 & & \\
\hline Manual laborers & 132 & $53(51.46)$ & $0.52(0.16-1.8)$ & 1.10 & 0.29 \\
\hline Others & 64 & $25(50.00)$ & $1.2(0.29-4.9)$ & 0.05 & 0.82 \\
\hline \multicolumn{6}{|l|}{ Household registration } \\
\hline Rural & 112 & $39(50.65)$ & 1.00 & & \\
\hline Urban & 707 & $241(43.11)$ & $0.91(0.29-2.9)$ & 0.02 & 0.88 \\
\hline \multicolumn{6}{|l|}{ History of childbirth } \\
\hline No & 524 & $172(41.55)$ & 1.00 & & \\
\hline Yes & 408 & $159(46.90)$ & $0.98(0.6-1.6)$ & 0.01 & 0.94 \\
\hline \multicolumn{6}{|l|}{ Number of lifetime sexual partners } \\
\hline 1 & 668 & $231(41.77)$ & 1.00 & & \\
\hline$\geq 2$ & 87 & $43(54.43)$ & $2.0(0.95-4.2)$ & 3.3 & 0.1 \\
\hline \multicolumn{6}{|c|}{ Prior experience with vaccinations outside the EPI (e.g., flu vaccine) } \\
\hline No & 810 & $279(42.27)$ & 1.0 & & \\
\hline Yes & 266 & $100(47.39)$ & $1.0(0.58-1.7)$ & $<0.001$ & 1.0 \\
\hline \multicolumn{6}{|l|}{ Fear of developing cervical cancer } \\
\hline No & 222 & $62(35.23)$ & 1.0 & & \\
\hline Yes & 586 & $243(49.90)$ & $1.8(1.06-3.2)$ & 4.6 & 0.0 \\
\hline \multicolumn{6}{|c|}{ Voluntarily sought out HPV-related information } \\
\hline No & 981 & $344(42.95)$ & 1.0 & & \\
\hline Yes & 82 & $39(55.71)$ & $1.4(0.64-3.2)$ & 0.8 & 0.4 \\
\hline
\end{tabular}

common beliefs that only women with multiple sexual partners need to be vaccinated.

Future directions for research include the development of a longitudinal, national HPV education program appropriate for school-based curriculum. Due to our limited participant sampling, our findings may not be generalized to the entire heterogeneous Chinese female population. Widespread implementation among different geographic regions and minority populations across China would shed light on the long-lasting impact of HPV education. Also, it is important develop evaluation and feedback tools to assess the effectiveness of the program. Lastly, follow-up studies must be performed to see if increased HPV and HPV vaccine knowledge translates into higher vaccination rates and vaccine compliance within China.

\section{Competing interests}

The authors declare that they have no competing interests.

\section{Authors' contributions}

IJC participated in data analysis and drafted the manuscript. FHZ and YLQ conceived of the design and coordination of the study. RH, WH and SKZ performed the statistical analysis. SMW and $\mathrm{RH}$ participated in the data collection. FZ guided the statistical analysis and revisions of the manuscript. All authors read and approved the final manuscript.

\section{Acknowledgements}

This work was supported by the Fogarty International Center, National Institutes of Health Office of the Director, Office of AIDS Research, National Cancer Center, National Heart, Blood, and Lung Institute, and the NIH Office of Research for Women's Health through the Fogarty Global Health Fellows 
Program Consortium comprised of the University of North Carolina, John Hopkins, Morehouse and Tulane (5R25TW009340-01).

\section{Author details}

'Department of Epidemiology, Cancer Institute of Chinese Academy of Medical Sciences, Peking Union Medical College, Beijing, P.R. China. ${ }^{2}$ University of Miami Miller School of Medicine, Miami, FL, USA. ${ }^{3}$ Gillings School of Global Public Health, University of North Carolina, Chapel Hill, NC, USA.

Received: 10 April 2013 Accepted: 5 September 2013 Published: 2 October 2013

\section{References}

1. Shi J-F, Qiao Y-L, Smith JS, Dondog B, Bao Y-P, Dai M, Clifford GM, Franceschi S: Epidemiology and prevention of human papillomavirus and cervical cancer in China and Mongolia. Vaccine 2008, 26(Suppl 12):M53-M59.

2. Ferlay J, Shin H-R, Bray F, Forman D, Mathers C, Parkin DM: Estimates of worldwide burden of cancer in 2008: GLOBOCAN 2008. Int J Cancer 2010, 127:2893-2917.

3. Yang L, Parkin DM, Li L, Chen Y: Time trends in cancer mortality in China: 1987-1999. Int J Cancer 2003, 106:771-783.

4. Qiao YL, Franceschi S, Belinson JL, et al: HPV prevalence in chinese women: a population-based multiple center survey in Mainland China. Oral presentation 1B-01, 24th international papillomavirus conference and clinical workshop. Beijing: Beijing International Convention Center; 2007.

5. Zhao F, Hu S, Zhang S, Chen W, Qiao Y: Cervical cancer mortality in 20042005 and changes during last 30 years in China. Zhonghua Yu Fang Yi Xue Za Zhi 2010, 44:408-412.

6. Bosch FX, Muñoz N: The viral etiology of cervical cancer. Virus Res 2002, 89:183-190.

7. Chen W, Zhang X, Molijn A, Jenkins D, Shi J-F, Quint W, Schmidt JE, Wang P, Liu Y-L, Li L-K, Shi H, Liu J-H, Xie X, Niyazi M, Yang P, Wei L-H, Li L-Y, Li J, Liu J-F, Zhou Q, Hong Y, Li L, Li Q, Zhou H-L, Bian M-L, Chen J, Qiao Y-L, Smith JS: Human papillomavirus type-distribution in cervical cancer in China: the importance of HPV 16 and 18. Cancer Causes Control 2009, 20:1705-1713.

8. Li J, Kang L-N, Qiao Y-L: Review of the cervical cancer disease burden in mainland China. Asian Pac J Cancer Prev 2011, 12:1149-1153.

9. Koutsky LA, Ault KA, Wheeler CM, Brown DR, Barr E, Alvarez FB, Chiacchierini LM, Jansen KU: A controlled trial of a human papillomavirus type 16 vaccine. N Engl I Med 2002, 347:1645-1651.

10. Poland GA, Jacobson RM, Koutsky LA, Tamms GM, Railkar R, Smith JF, Bryan JT, Cavanaugh PF Jr, Jansen KU, Barr E: Immunogenicity and reactogenicity of a novel vaccine for human papillomavirus 16: a 2-year randomized controlled clinical trial. Mayo Clin Proc 2005, 80:601-610.

11. Lehtinen M, Apter D, Dubin G, Kosunen E, Isaksson R, Korpivaara E-L, KyhäOsterlund L, Lunnas T, Luostarinen T, Niemi L, Palmroth J, Petäjä T, Rekonen S, Salmivesi S, Siitari-Mattila M, Svartsjö S, Tuomivaara L, Vilkki M, Pukkala E, Paavonen J: Enrollment of 22,000 adolescent women to cancer registry follow-up for long-term human papillomavirus vaccine efficacy: guarding against guessing. Int J STD AIDS 2006, 17:517-521.

12. FUTURE II Study Group: Quadrivalent vaccine against human papillomavirus to prevent high-grade cervical lesions. N Engl J Med 2007, 356:1915-1927.

13. Friedman AL, Shepeard H: Exploring the knowledge, attitudes, beliefs, and communication preferences of the general public regarding HPV: findings from $C D C$ focus group research and implications for practice. Health Educ Behav 2007, 34:471-485.

14. Brewer NT, Fazekas KI: Predictors of HPV vaccine acceptability: a theoryinformed, systematic review. Prev Med 2007, 45:107-114

15. De Visser R, McDonnell E: Correlates of parents' reports of acceptability of human papilloma virus vaccination for their school-aged children. Sex Health 2008, 5:331-338.

16. Li J, Li L-K, Ma J-F, Wei L-H, Niyazi M, Li C-Q, Xu A-D, Wang J-B, Liang H, Belinson J, Qiao Y-L: Knowledge and attitudes about human papillomavirus (HPV) and HPV vaccines among women living in metropolitan and rural regions of China. Vaccine 2009, 27:1210-1215.

17. Kwan TTC, Chan KKL, Yip AMW, Tam KF, Cheung ANY, Lo SST, Lee PWH, Ngan HYS: Acceptability of human papillomavirus vaccination among Chinese women: concerns and implications. BJOG 2009, 116:501-510.
18. Zhao F-H, Tiggelaar SM, Hu S-Y, Zhao N, Hong Y, Niyazi M, Gao X-H, Ju L-R, Zhang L-Q, Feng X-X, Duan X-Z, Song X-L, Wang J, Yang Y, Li C-Q, Liu J-H, Liu J-H, Lu Y-B, Li L, Zhou Q, Liu J-F, Xu L-N, Qiao Y-L: A multi-center survey of HPV knowledge and attitudes toward HPV vaccination among women, government officials, and medical personnel in China. Asian PaC J Cancer Prev 2012, 13:2369-2378.

19. Reiter PL, Stubbs B, Panozzo CA, Whitesell D, Brewer NT: HPV and HPV vaccine education intervention: effects on parents, healthcare staff, and school staff. Cancer Epidemiol Biomarkers Prev 2011, 20:2354-2361.

20. Hopfer S: Effects of a narrative HPV vaccination intervention aimed at reaching college women: a randomized controlled trial. Prev Sci 2012, 13:173-182.

21. Gottvall M, Tydén T, Höglund AT, Larsson M: Knowledge of human papillomavirus among high school students can be increased by an educational intervention. Int J STD AIDS 2010, 21:558-562.

22. Oh J-K, Lim MK, Yun EH, Lee E-H, Shin H-R: Awareness of and attitude towards human papillomavirus infection and vaccination for cervical cancer prevention among adult males and females in Korea: a nationwide interview survey. Vaccine 2010, 28:1854-1860.

23. Uzunlar O, Ozyer S, Başer E, Toğrul C, Karaca M, Güngör T: A survey on human papillomavirus awareness and acceptability of vaccination among nursing students in a tertiary hospital in Ankara. Vaccine: Turkey; 2013.

24. Tonguc E, Gungor T, Var T, Kavak E, Yucel M, Uzunlar O: Knowledge about HPV, relation between HPV and cervix cancer and acceptability of HPV vaccine in women in eastern region of Turkey. J Gynecol Oncol 2013, 24:7-13.

25. Lee PWH, Kwan TTC, Tam KF, Chan KKL, Young PMC, Lo SST, Cheung ANY, Ngan HYS: Beliefs about cervical cancer and human papillomavirus (HPV) and acceptability of HPV vaccination among Chinese women in Hong Kong. Prev Med 2007, 45:130-134

26. Kwan TTC, Tam K, Lee PWH, Chan KKL, Ngan HYS: The effect of schoolbased cervical cancer education on perceptions towards human papillomavirus vaccination among Hong Kong Chinese adolescent girls. Patient Educ Couns 2011, 84:118-122.

27. Kwan TTC, Lo SST, Tam K-F, Chan KKL, Ngan HYS: Assessment of knowledge and stigmatizing attitudes related to human papillomavirus among Hong Kong Chinese healthcare providers. Int J Gynaecol Obstet 2012, 116:52-56.

28. Hanley SJB, Yoshioka E, Ito Y, Konno R, Hayashi Y, Kishi R, Sakuragi N Acceptability of and attitudes towards human papillomavirus vaccination in Japanese mothers of adolescent girls. Vaccine 2012, 30:5740-5747.

29. Guzalnur A, Xamxinuer A: The relationships between cervical cancer of Uighur women and the knowledge about cervical cancer. Maternal and Child Health Care of China 2007, 31:25-28.

30. Ren C-L, Hou S-M, Zhang S-P, Hou H-Y, Zhang S-X: Knowledge popularization status on cancer in cervix in Han, Hui and Uygur Chinese females in Malan area. Medical J Gen Equip Heada 2011, 4

doi:10.1186/1471-2458-13-916

Cite this article as: Chang et al:: Effect of an educational intervention on HPV knowledge and vaccine attitudes among urban employed women and female undergraduate students in China: a cross-sectional study. BMC Public Health 2013 13:916.

\section{Submit your next manuscript to BioMed Central and take full advantage of:}

- Convenient online submission

- Thorough peer review

- No space constraints or color figure charges

- Immediate publication on acceptance

- Inclusion in PubMed, CAS, Scopus and Google Scholar

- Research which is freely available for redistribution 